\title{
REFUGIADOS NICARAGÜENSES Y DESPLAZADOS EN HONDURAS EN LA DÉCADA DE LOS OCHENTA
}

\author{
NICARAGUAN REFUGEES AND HONDURANS DISPLACED \\ DURING THE 80'S \\ Elvia Elizabeth Gómez García \\ Universidad Tecnológica Centroamericana UNITEC, San Pedro Sula, Honduras
}

\begin{abstract}
RESUMEN: El presente artículo tiene como objetivos describir la situación de los refugiados nicaragüenses establecidos en el departamento de El Paraíso, en la región oriental de Honduras a partir del triunfo de la revolución sandinista en Nicaragua en 1979, así como el de establecer la relación existente entre el surgimiento de los desplazados de guerra hondureños y el asentamiento de los contrarrevolucionarios nicaragüenses en dicho país. Honduras se convirtió en receptora de refugiados provenientes de los países vecinos en conflicto, y al mismo tiempo en la base de operaciones de los grupos contrainsurgentes que tenían como finalidad derrocar al régimen sandinista de Nicaragua. El presente trabajo se centra en el análisis documental y la recolección de información mediante entrevistas haciendo uso de fuentes primarias y secundarias, intentando profundizar en dos fenómenos fundamentales de esta etapa, los refugiados nicaragüenses y los desplazados de guerra.
\end{abstract}

PALABRAS CLAVES: Refugiados, desplazados, ACNUR, Contras.

ABSTRACT: This article aims to describe the situation of Nicaraguan refugees settled in the department of El Paraiso, in the east of Honduras, after the Sandinista's revolution victory in 1979 as well as to stablish the relationship between the emergence of Honduran war-displaced and the Nicaraguan counter-revolutionary settlements in this country. Honduras became the recipient of refugees coming from the neighbor countries in conflict and also the operations base to counterinsurgency groups which objective was to overthrow the Nicaraguan Sandinist regime. The present work focuses on the documentary analysis and gathering of information by means of interviews. It makes use of primary and secondary sources trying to analyze in depth two fundamental phenomena of this time, the Nicaraguan refugees and the war-displaced.

KEY WORDS: Refugees, displaced, ACNUR, Contras.

* Correspondencia a: Elvia Elizabeth Gómez García. UNITEC San Pedro Sula. Calle hacia Armenta, contiguo a Altia Business Park. San Pedro Sula. Honduras. - elvia.gomez@unitec.edu.hn - https://orcid.org/0000-0001-7063-7259

Cómo citar: Gómez García, Elvia Elizabeth (2021). «Refugiados nicaragüenses y desplazados en Honduras en la década de los ochentas»; Historia Contemporánea, 65, 163-195. (https://doi.org/10.1387/hc.21013).

Recibido: 11 julio, 2019; aceptado: 15 noviembre, 2019.

ISSN 1130-2402 - eISSN 2340-0277 / (C) 2020 UPV/EHU 


\section{Introducción}

El presente artículo parte de la exposición breve de la situación de la región centroamericana a partir del triunfo de la revolución sandinista en Nicaragua, planteando los conflictos inherentes a cada uno de los países expulsores de migrantes, así como la situación de Honduras, a fin de comprender el contexto bajo el cual surge la problemática en la cual se centra la investigación. Se hace una descripción de la situación de los refugiados nicaragüenses específicamente, a partir del planteamiento de los elementos relacionados con el tema en las leyes vigentes en Honduras en la época en que surgió la problemática. De igual forma se establecen las diferencias existentes en las tipificaciones de refugiados nicaragüenses que fueron establecidas por el Alto Comisionado de las Naciones Unidas para Refugiados (ACNUR). Una vez planteado el tema de los refugiados se aborda, como producto de dicha problemática, el surgimiento de los desplazados de guerra, población hondureña afectada por las acciones de los grupos armados contrarrevolucionarios establecidos en la zona fronteriza entre Honduras y Nicaragua. Si bien la temática de los desplazamientos forzados ya ha sido abordada en otros trabajos, ${ }^{1}$ estos se han centrado en los casos de El Salvador, Guatemala y Nicaragua, con muy poco o ningún énfasis en la situación de Honduras, que se convirtió tanto en receptor de población refugiada de los países antes mencionados como en emisor de desplazados internos. Los objetivos del presente artículo son el describir las acciones emprendidas por los gobiernos de Honduras de la década de los ochentas en materia de refugiados, así como las medidas implementadas con relación a los desplazados internos producto de la instalación del grupo armado de los contras en el territorio nacional.

El fin de la segunda guerra mundial marcó el inicio de un nuevo conflicto internacional que enfrentó a dos ideologías contrapuestas. Estados Unidos y la Unión de Repúblicas Socialistas Soviéticas iniciaron una carrera no solo armamentista, sino también de expansión de sus respectivas ideologías a nivel mundial. Pese a la lejanía geográfica de la URSS, el triunfo de la revolución cubana significó la llegada de su ideología a una región que históricamente estuvo vinculada al domino de Estados Unidos. A partir de 1959, el fortalecimiento de los denominados grupos de izquierda comenzó a manifestarse en toda América Latina y esto significó

1 Véase para el caso Montes, S. (1989), p. 16,31; Aguayo, S. (1985); Alonso, J. (1992). 
la amenaza de la expansión comunista y por supuesto, a los intereses económicos y geoestratégicos de Estados Unidos en lo que se ha denominado como su «patio trasero». Centroamérica no fue la excepción a esta oleada revolucionaria y países como Nicaragua y El Salvador, que ya contaban con movimientos previos como los de Augusto Cesar Sandino y su guerra nacional contra la ocupación militar estadounidense, y Agustín Farabundo Martí y su levantamiento armado contra la dictadura de Maximiliano Hernández respectivamente en la década de los 1930's, se convirtieron en el escenario del fortalecimiento de sus movimientos que dieron origen al Frente Sandinista para la Liberación Nacional (FSLN) y el Frente Farabundo Martí para la Liberación Nacional (FMLN). Tanto Sandino como Martí se conocieron en México en 1929 y ambos fueron los impulsores de los partidos comunistas en sus respectivos países.

Por su parte, Guatemala, que ya había tenido un intento fallido de un gobierno de corte progresista de la mano de Jacobo Arbenz, quien sufrió un golpe de Estado en 1954 orquestado por Estados Unidos y apoyado por el gobierno de Honduras, que prestó su territorio para la incursión de columnas de mercenarios encargados de debilitar el régimen; llegará a la década de los sesenta envuelta en levantamientos insurreccionales y fortalecimiento de sus grupos rebeldes, que más adelante se agruparon en una sola organización, La Unión Revolucionaria Nacional Guatemalteca (URNG). Ante estos acontecimientos en el istmo centroamericano la política internacional de Estados Unidos comenzó a sufrir una serie de transformaciones, con la finalidad de levantar un muro de contención a la expansión comunista en la región. Lo anterior se puede comprender si tomamos como base la teoría dominó ${ }^{2}$, que en política internacional planteaba que los países asemejaban a fichas de dominó y que, si una caía las demás harían lo mismo irremediablemente, y que sustentaba a la doctrina Truman, que surgió al finalizar la segunda guerra mundial y dar inicio la guerra fría. El triunfo de la revolución cubana fue la concretización del miedo a la expansión comunista en América y esto significaba para Estados Unidos y sus intereses la pérdida de su hegemonía en la región. Debido a ello, el presidente John F. Kennedy presentó en 1961 su programa Alianza para el Progreso (Alliance for Progress), un programa que incluía ayuda económica, política y social con la finalidad de frenar el expansionismo comunista en la región y que, como planteó Walter Krause en un artículo

2 Tovar (2011), p. 170; Ninkovich 1981 y Agnew 2005. 
denominado con ese nombre, en un tiempo record se confeccionó un programa de asistencia que tuvo una respuesta en general favorable y que fue dado a conocer en $1961 .^{3}$

Ni la Alianza para el Progreso logró frenar el descontento social hacia los regímenes militares impuestos en los países del triángulo norte, ya sea como gobiernos producto de golpes de Estado o como dictaduras militares, y en el año de 1979 se produjo el triunfo de la revolución sandinista en Nicaragua. Esto en cierta medida, comprobó la denominada teoría dominó pues, como producto de la misma, El Salvador entró a una guerra civil en 1980 y Guatemala vio el recrudecimiento del conflicto armado, todos ellos sustentados en una ideología comunista. En medio de este clima conflictivo se encontraba Honduras, un país que siempre ha dependido de Estados Unidos para poder sostener su economía y que se convirtió en la base de operaciones del país del norte para la implementación de su política internacional hacia los países antes mencionados, convirtiéndose en el «patio trasero» donde se planificaban y ordenaban las acciones a seguir con la finalidad de derrocar al régimen sandinista y frenar la expansión comunista en la región. El clima conflictivo experimentado en la década de los ochentas desembocó en el surgimiento de dos fenómenos de desplazamiento masivo de población hacia y en el territorio hondureño; los refugiados provenientes de Guatemala, El Salvador y Nicaragua y los desplazados internos que huían del clima bélico imperante en la región fronteriza entre Honduras y Nicaragua.

En la presente investigación se ha hecho uso de varias fuentes documentales, provenientes de organismos nacionales e internacionales, así como de centros de documentación y trabajo de campo a partir de entrevistas a personas que vivieron la problemática. De igual forma se ha hecho uso de fuentes secundarias como libros, periódicos y revistas que abordaron en su momento la temática.

\section{La crisis regional: un acercamiento al contexto centroamericano}

Desde 1937, Nicaragua se vio sometida a una dictadura militar conocida como el Somocismo, que respondió siempre a los intereses económicos de las compañías norteamericanas y contó con el apoyo de este país.

\footnotetext{
3 Krause, 1963.
} 
Durante la época de la dictadura, la población nicaragüense se vio sometida a un gobierno caracterizado por el terror y la represión, de la mano de la Guardia Nacional que fue fundada en 1934 para sustituir a los marines de Estados Unidos que habían invadido el territorio nicaragüense, argumentando la defensa de los intereses de los ciudadanos norteamericanos residentes en el mismo. Del fundador Anastasio Somoza se refirió el presidente Franklin Delano Roosevelt ${ }^{4}$ diciendo «Sí, es un hijo de puta, pero es nuestro hijo de puta» y de igual forma lo hizo Henry Kissinger ${ }^{5}$ al referirse a Anastasio Somoza Debayle quien en 1979 fue derrocado como producto del triunfo de una revolución popular liderada por el Frente Sandinista para la Liberación Nacional (FSLN) ${ }^{6}$ organizado en la década de los sesentas y que tuvo como uno de sus fundadores a Carlos Fonseca. Lo anterior se tradujo para los intereses norteamericanos en la llegada del comunismo a la región. Ante tal situación, los demás países centroamericanos celebraron elecciones presidenciales en los primeros años de la década de los ochentas, con la finalidad de reconstituir la legalidad, pues los regímenes militares habían sido hasta la fecha los encargados de gobernar en ellos, exceptuando a Costa Rica en donde el proceso democrático no se había interrumpido. El primer paso fue la elección de asambleas constituyentes ${ }^{7}$ encargadas de redactar una nueva constitución que permitiera el retorno de los civiles al poder, quienes debían hacer frente a los problemas internos agudizados por la crisis económica regional y el incremento de los índices de pobreza. Las elecciones realizadas en estos países contaron con algunos rasgos comunes, Torres (1992) plantea que:

En primer lugar no han sido elecciones fraudulentas, ningún contendiente las ha impugnado y han sido consideradas como sufragios técnicamente libres... En tercer lugar, aunque el juego de partidos es

${ }^{4}$ Franklin Delano Roosevelt fue el trigésimo segundo presidente de los Estados Unidos desde 1933 hasta su muerte en 1945, durante su gobierno se implementó la denominada «política del buen vecino» en América Latina.

5 Henry A. Kissinger fue Secretario de Estado de Estados Unidos durante la presidencia de Richard Nixon.

${ }^{6}$ El FSLN surge como una organización político militar en el año de 1961 con la finalidad de derrocar a la dictadura de la familia Somoza, tomando como base la imagen de Augusto Cesar Sandino quien lideró los alzamientos en contra de la injerencia de Estados Unidos en su país. Para más información Pisani, 1981 y Alegría y Flakoll, D. J, 1982.

${ }^{7}$ Las asambleas constituyentes son organismos colegiados cuya finalidad es la de redactar la nueva constitución de la República y preparar el camino hacia los procesos electorales. 
limitado en su pluralismo pragmático e ideológico ha sido libre y competitivo, otorgando el triunfo a fuerzas políticamente conservadoras... En cuarto lugar, los candidatos presidenciales han sido civiles que en el pasado inmediato estuvieron en franca oposición a los gobiernos militar. En quinto lugar, las elecciones fueron procesos de consulta sobre vigilada por una legión de observadores extranjeros, periodistas y otros ojos dispuestos a garantizar o descalificar el evento. (p. 20)

Pero el retorno a la democracia no se dio en igualdad de condiciones para el triángulo norte de Centroamérica. En 1979, El Salvador vislumbró el ascenso al poder de las juntas revolucionarias de gobierno (JRG) ${ }^{8}$, las cuales estuvieron en el poder hasta el año de 1982 y fue en el marco de las mismas que se produjo el estallido de la guerra civil. Debido a que las juntas no lograron estabilizar la situación del país, en ese mismo año (1982) se instaló una asamblea constituyente que nombró como presidente provisional a Álvaro Magaña, mientras se celebraban los comicios electorales de 1984 en los cuales fue electo presidente José Napoleón Duarte. Su gobierno recibió el apoyo incondicional del presidente estadounidense Ronald Reagan, el cual incrementó considerablemente su asistencia militar. Bajo esta dinámica de cambios de gobierno se constituyó en 1980 el Frente Farabundo Martí para la Liberación Nacional (FMLN) ${ }^{9}$, el cual estuvo conformado por cinco estructuras políticas existentes en este país; el Partido Comunista de El Salvador (PCS), las Fuerzas Populares de Liberación «Farabundo Martí» (FPL), el Ejército Revolucionario del Pueblo (ERP), la Resistencia Nacional (RN) y el Partido Revolucionario de los Trabajadores Centroamericanos (PRTC), todas ellas hacían frente a las políticas represivas del Estado y desembocaron en el desarrollo de una guerra civil que se extendió hasta finales de la década de los ochenta. En Guatemala por su parte, el país se encontraba sumido en una profunda crisis política, producto del derrocamiento del gobierno de Jacobo Arbenz ${ }^{10}$ en 1954, orquestado por el gobierno de Estados Unidos que lo tildó de izquierdista y de ser una amenaza a la democracia de la región. A partir de

8 Junta Revolucionaria de Gobierno (JRG) es el nombre con que se conoce a tres gobiernos de facto que hubo en El Salvador desde 1979 hasta 1982.

9 El Frente Farabundo Martí para la Liberación Nacional toma su nombre del revolucionario Agustín Farabundo Martí, fundador del Partido Comunista de El Salvador en 1930.

10 Jacobo Arbenz fue un militar guatemalteco con ideas progresista que asume la presidencia por medio de elecciones en 1950. Durante su gobierno expropió tierras a la compañía bananera United Fruit Company, de capital norteamericano. 
ese momento las organizaciones de izquierda existentes en el país comenzaron a ser el blanco de la persecución de los gobiernos sucesivos y la suspensión de la reforma agraria impulsada por Arbenz contribuyó al involucramiento del sector campesino en la lucha armada. De esta forma, los gobiernos de turno implementaron el terrorismo de Estado que contribuyó al traslado de sectores urbanos a la lucha armada. Las organizaciones revolucionarias de Guatemala eran diversas y entre ellas podemos mencionar al ejército guerrillero de los pobres (EGP), la organización del pueblo en armas (ORPA), las fuerzas armadas rebeldes (FAR) y el Partido Guatemalteco del Trabajo (PGT), todas ellas se agruparon en lo que se denominó como la Unidad Revolucionaria Nacional Guatemalteca $(\mathrm{URNG})^{11}$. Guatemala entró a la década de los ochenta de la mano del militar Fernando Romeo Lucas García, electo mediante el voto popular en 1978 y en cuyo gobierno se produjo el incremento de la actividad guerrillera y la incorporación de los indígenas en la lucha armada. En 1982 asumió la presidencia tras un golpe militar Efraín Ríos Montt, quien ocupó el cargo hasta 1983. Sobre el gobierno de Ríos Montt, Figueroa (1992) nos plantea que:

... la dictadura militar encabezada por Ríos Montt elevaría de 15,000 a 500,000 los hombres organizados en las patrullas de Autodefensa Civil (las cuales llegarían a contar con casi un millón durante la época de Mejía Victores). También elevaría el terrorismo de estado a un nivel superior al convertirlo en un dispositivo masivo que implicó aproximadamente 300 masacres en pueblos indígenas del altiplano central y occidental, 16,000 muertos y 90,000 refugiados en los países vecinos y aproximadamente un millón de desplazados internos (en comparación con el medio millón que se observó en El Salvador). (pp. 53,54)

Las patrullas de autodefensa civil fueron grupos paramilitares formados y dirigidos por los militares guatemaltecos, conformadas por civiles voluntarios quienes se encargaban de vigilar, perseguir y detectar a guerrilleros o posibles guerrilleros. Las acciones represivas y los crímenes de lesa humanidad cometidos por el régimen de Ríos Montt llevaron a su derrocamiento por parte del general de brigada Oscar Umberto Mejía, que permaneció en el poder hasta 1986, cuando un civil asume la presidencia

11 La URNG se constituyó en partido político. 
después de la celebración de elecciones que dieron como ganador a Marco Vinicio Cerezo, quien fue uno de los participantes en las negociaciones y firmas de los tratados de paz de Centroamérica.

En el centro de este huracán se encontraba Honduras, en donde la tradición bipartidista se vio reflejada en el proceso electoral celebrado en 1981, después de casi dos décadas de gobiernos militares, cuyos comicios fueron ganados por el Partido Liberal quien presentó como candidato al civil Dr. Roberto Suazo Córdova, quien asumió la presidencia acompañado del Gral. Gustavo Álvarez Martínez como comandante en jefe de las Fuerzas Armadas. Muchos teóricos como Posas (1989) catalogaron al gobierno de Córdova como una democracia tutelada y restringida y que los militares siguieron teniendo una cuota elevada de poder en el gobierno. Una vez que Álvarez Martínez asumió el cargo, se puso en marcha la implementación de la Doctrina de la Seguridad Nacional (DSN) ${ }^{12}$, cuya finalidad era la de frenar el avance del comunismo en el país a través de la implementación de mecanismos de represión selectiva. Dentro de dicha política y bajo el asesoramiento del gobierno de Estados Unidos que nombró como embajador para Honduras a John Dimitri Negroponte ${ }^{13}$, quien contaba con una amplia experiencia diplomática y militar, Negroponte formó parte de la Agencia Central de Inteligencia (CIA) y mientras fungió como embajador se formó el escuadrón 3-16 14 que aplicaba métodos de tortura, detención y desaparición extrajudicial. El gobierno de Suazo Córdova estableció un estrecho vínculo con el gobierno norteamericano que incrementó la asistencia económica y militar en el país. Vilas (1993) nos plantea que:

El rol protagónico que el país desempeñaba en el conflicto regional-especialmente el de «santuario de la contra»-facilitó esa afluencia y determinó que los fondos directos provenientes del gobierno estado-

12 La Doctrina de Seguridad Nacional surgió en el marco de la guerra fría y se implementó en América Latina con la finalidad de controlar a la oposición política que manifestase una tendencia izquierdista. Para saber más puede consultar a Leal, 1994.

13 John Dimitri Negroponte fue nombrado embajador de Honduras en 1981 y fungió en su cargo hasta 1985. Era considerado el tercer hombre más poderoso del país y se le vincula a la implementación de la guerra sucia contra Nicaragua.

${ }^{14}$ El escuadrón 3-16 es el nombre asignado al batallón de inteligencia constituido en Honduras en 1984 y que se encargó del secuestro y desaparición de personas pertenecientes a la oposición política o considerados una amenaza por sus ideales. Se le conoce también como escuadrón de la muerte y estuvo bajo la dirección de Billy Joya. 
unidense llegaran en cantidades bastante significativas. Así, en 1985 Estados Unidos otorgó al país US \$282.6 millones, 67.4 de los cuales se destinaron a fines militares; durante 1987 la asistencia norteamericana total ascendió a US 4260.6 millones, que incluían 61.2 millones que se utilizarían en actividades militares. (p. 248)

El gobierno de Ronald Reagan consideró a Honduras su pieza clave para la implementación de su política exterior en Centroamérica, En la época en que Negroponte fungió como embajador había un promedio de 400 diplomáticos acreditados en el país, lo que convirtió a esta embajada en la tercera más numerosa de América Latina. Estados Unidos hizo uso del territorio hondureño para atacar al régimen nicaragüense, valiéndose para ello de la realización de maniobras de entrenamiento militar, presencia de asesores y soldados norteamericanos en territorio hondureño y el establecimiento de la base militar de Palmerola en el departamento de Comayagua, en el centro del país, así como la construcción de diversas pistas de aterrizaje localizadas en puntos estratégicos del territorio como el centro regional de entrenamiento militar $(\mathrm{CREM})^{15}$ en el departamento de Colón, en la zona costera del norte del país y la base de El Aguacate en el departamento de Olancho. El nuevo gobierno tal como lo plantea Posas (1989) «debía compartir el poder estatal con los militares hondureños quienes no abandonaron plenamente el aparato estatal, ya que continuaron reteniendo el control sobre todas aquellas instituciones estatales que a su juicio estaban relacionadas con la seguridad interna del país». (p. 85)

En los nuevos comicios celebrados en 1985 el partido de gobierno se alzó nuevamente con la victoria y asumió la presidencia en 1986 José Simón Azcona del Hoyo, cuyo gobierno careció de la autoridad suficiente para establecer un verdadero programa que superara la profunda crisis económica en la que se encontraba el país. La presencia de la contra en el territorio nacional creó un clima desfavorable para el nuevo gobierno, que se limitó a negar la existencia de los mismos. Fue durante su gobierno que dieron inicio las negociaciones para la firma

${ }^{15}$ El CREM fue un centro militar creado en la década de los ochentas para la realización de maniobras militares combinadas en las cuales participaban elementos de las fuerzas armadas de Honduras y El Salvador, quienes eran entrenados por militares norteamericanos en tácticas de guerra de guerrillas. Sirvió también para el entrenamiento de elementos pertenecientes a la contrarrevolución nicaragüense. 
de los tratados de paz en Centroamérica conocidos como Esquipulas I y Esquipulas II. ${ }^{16}$.

\section{Refugiados: aspectos conceptuales}

En 1950 la Organización de las Naciones Unidas decidió crear el Alto Comisionado de las Naciones Unidas para los Refugiados, conocido en sus siglas como ACNUR (de ahora en adelante nos referiremos a este organismo bajo sus siglas), con la finalidad de brindar asistencia a las víctimas de la segunda guerra mundial. En 1951 se emitió la Convención sobre el Estatuto de los Refugiados que se convirtió en el fundamento legal para las acciones a implementar por parte de dicho organismo y que tomó como base la carta de las Naciones Unidas y la Declaración Universal de los Derechos Humanos, en aras de velar porque los refugiados gozaran de los derechos y las garantías fundamentales.

Según la convención sobre el estatuto de los refugiados:

...el término «refugiado» se aplicará a toda persona: 1) Que haya sido considerada como refugiada en virtud de los Arreglos del 12 de mayo de 1926 y del 30 de junio de 1928, o de las Convenciones del 28 de octubre de 1933 y del 10 de febrero de 1938, del Protocolo del 14 de septiembre de 1939 o de la Constitución de la Organización Internacional de refugiados. 2) Que, como resultado de acontecimientos ocurridos antes del 1. ${ }^{\circ}$ de enero de 1951 y debido a fundados temores de ser perseguida por motivos de raza, religión, nacionalidad, pertenencia a determinado grupo social u opiniones políticas, se encuentre fuera del país de su nacionalidad y no pueda o, a causa de dichos temores, no quiera acogerse a la protección de tal país; o que, careciendo de nacionalidad y hallándose, a consecuencia de tales acontecimientos, fuera del país donde antes tuviera su residencia habitual, no pueda o, a causa de dichos temores, no quiera regresar a él. (pp. 1,2)

Como se observa en la cita anterior, la convención de 1951 limitaba el término de refugiados a aquellos ciudadanos que adquirían tal con-

\footnotetext{
${ }^{16}$ Los tratados de paz en Centroamérica surgieron como parte de los esfuerzos realizados por el presidente de Costa Rica Oscar Arias, quien propuso en 1987 el denominado Plan Arias para la Paz. Para saber más puede remitirse a http://www.uca.edu.sv/centro-documentacion-virtual/wp-content/uploads/2015/03/C13-c14-.pdf
} 
dición a partir de los acontecimientos ocurridos antes del 1 de enero de 1951, por lo que el radio de acción del ACNUR en materia de protección se veía enmarcado en esa temporalidad y por ende era excluyente. Con la finalización de la segunda guerra mundial, se dio el surgimiento de otro conflicto que se denominó como la guerra fría, en el cual surgieron nuevas situaciones que propiciaron la existencia de otros refugiados que quedaron fuera de lo establecido en la convención de 1951. Debido a lo anterior en octubre de 1967 entró en vigencia un Protocolo ${ }^{17}$ sobre el estatuto de los refugiados que amplió el concepto del mismo y estableció que:

Artículo I. Disposiciones generales. 1.- Los Estados Partes en el presente Protocolo se obligan a aplicar los artículos 2 a 34 inclusive de la Convención a los refugiados que por el presente se definen. 2. A los efectos del presente Protocolo y salvo en lo que respecta a la aplicación del párrafo 3 de este artículo, el término «refugiado» denotará toda persona comprendida en la definición del artículo 1 de la Convención, en la que se darán por omitidas las palabras «como resultado de acontecimientos ocurridos antes del 1. ${ }^{\circ}$ de enero de 1951 y ...» y las palabras «... a consecuencia de tales acontecimientos», que figuran en el párrafo 2 de la sección A del artículo.3. El presente Protocolo será aplicado por los Estados Partes en el mismo sin ninguna limitación geográfica; no obstante, serán aplicables también en virtud del presente Protocolo las declaraciones vigentes hechas por Estados que ya sean Partes en la Convención de conformidad con el inciso a del párrafo 1 de la sección $\mathrm{B}$ del artículo 1 de la Convención, salvo que se hayan ampliado conforme al párrafo 2 de la sección B del artículo 1. (p. 1)

Fue hasta el 23 de marzo de 1992 que Honduras hizo la adhesión ${ }^{18}$ a la Convención y al Protocolo, doce años después de la llegada de refugiados provenientes de Guatemala, El Salvador y Nicaragua, por lo que la aplicabilidad de ambos instrumentos en el país estaba sujeta a las leyes vigentes en ese momento, considerando en las mismas la Constitución de la República de 1965 y la de 1982, así como la nueva Ley de Población y Política Migrato-

17 Se entiende por protocolo un anexo a un tratado inicial.

18 Se entiende por adhesión el acto por el cual un Estado que no ha firmado un tratado expresa su consentimiento en llegar a ser parte en ese tratado depositando «un instrumento de adhesión». 
ria ${ }^{19}$ emitida en el mes de septiembre de 1970 que dejaba sin efecto las leyes de Inmigración de 1934, de Extranjería de 1946 y de Identidad de 1953. En la misma no se contemplaba la definición de refugiado, pero si encontramos artículos relacionados con los casos en los cuales no se permitiría la entrada de los extranjeros al territorio nacional. Entre ellos, en el Capítulo VIII, artículo 30 , inciso d, se plantea que: aquellos extranjeros que: aconsejen, enseñen o practiquen la desobediencia de las leyes o autoridades hondureñas, el derrocamiento del gobierno por medio de la violencia y el desconocimiento del derecho de propiedad; que sean opositores a todo gobierno organizado o al sistema de gobierno republicano, democrático y representativo (p.11)

De igual forma en el capítulo 10 de dicha ley bajo el enunciado Control de extranjeros en casos especiales, el artículo 41 establece que: Con el objeto que el gobierno de Honduras, pueda conservar la más estricta neutralidad en los asuntos de política interna o externa que se susciten en otros países, la Secretaría de Gobernación y Justicia, tomará las medidas conducentes para impedir que los extranjeros participen en actividades bélicas que propendan a iniciar o fomentar guerras civiles o conflictos internacionales entre otros Estados.(p. 13)

En el artículo 43 de la misma ley, que plantea la expulsión de extranjeros, se establece que:

El Poder Ejecutivo procederá a expulsar a todo extranjero que se halle comprendido en los casos siguientes: 5. Los que, por cualquier medio, ultrajen la dignidad nacional o se hayan dedicado o se dedicaren a la propaganda de doctrinas o teorías contrarias a la moral y al sistema constitucional del país. 6.Los que provocare manifestaciones contrarias al orden establecido y los que hayan enviado o enviaren al extranjero noticias o informaciones tendenciosas o falsas con el objeto de desprestigiar al país y a su régimen.7. Los que tomaren parte en disensiones civiles, rebelión, sedición y huelga ilegal. 8.Los que tomaren parte en motines o favorecieren o impulsaren de cualquier modo conflictos de carácter internacional. (p. 14)

De igual forma esta ley establecía dos tipologías con relación a los extranjeros, a los cuales hace referencia como inmigrantes y no inmigrantes, entendiendo según la ley en su artículo 46 que es inmigrante «el extranjero

19 Para consultar la Ley de Población y Política Migratoria de 1970 puede remitirse al Diario oficial la Gaceta, número 20247, 10 de diciembre de 1970. 
que ingresa legal o condicionalmente al país con el propósito de radicarse en él» (p. 15). Así mismo, en el artículo 51 se establece que «los inmigrantes podrán ser asistidos y dirigidos por el Estado para su ingreso en el territorio nacional, ya sea en forma directa o mediante la colaboración de organismos internacionales o de otras instituciones creadas con ese objeto». (p. 16)

La misma Ley establece que es un no inmigrante el extranjero que ingrese al país de manera temporal y con el permiso correspondiente. A este respecto contempla dentro de los permisos el de asilado político y al respecto en el capítulo XV, artículo 73, numeral 4: Como asilado político, autorizado por el tiempo que se juzgue conveniente atendiendo a las circunstancias que en cada caso concurran. Si el asilado político se ausenta del país perderá todo derecho a regresar, salvo que haya salido con permiso expreso de la Secretaría de Gobernación y Justicia. (p. 25)

Bajo este marco legal, Honduras observó a partir de 1979 la llegada de miles de refugiados provenientes de las vecinas Guatemala, El Salvador y Nicaragua que huían de la situación conflictiva en sus países. Entre 1979 y 1980 más de 30,000 refugiados, en su mayoría salvadoreños en ese momento habían buscado refugio en el territorio. Debido a ello el ACNUR intervino por primera vez en Centroamérica ante la crisis humanitaria que tuvo como escenario el territorio hondureño, para 1981 el programa de asistencia a refugiados de ACNUR en Honduras era el más importante en toda América Latina. En una memoria publicada por el organismo a 50 años de su fundación, ACNUR (2000) definió así los campamentos de refugiados: «son zonas cerradas y limitadas para los refugiados y las personas que los asisten, donde se proporciona protección y asistencia hasta que los refugiados puedan retornar sin riesgo a sus países de origen o ser reubicados en otro lugar» (p. 120)

Ante la situación cada vez más delicada y al no existir leyes inherentes a la temática de los refugiados, el gobierno de Policarpo Paz García ${ }^{20}$ crea la Comisión Nacional para los Refugiados (CONARE) a través del decreto \#13 del 21 de enero de 1981. El organismo estuvo conformado por el entonces Ministro de Gobernación y Justicia, el Ministro del Exterior, el Ministro de Defensa y Seguridad Pública y el Ministro de Asistencia Social, Salud y Labor. El coordinador de la CONARE de 1981 a 1982 fue el coronel Abraham García Turcios. Es importante recalcar que para

${ }^{20}$ Policarpo Paz García fue el último presidente militar en Honduras, uno de los integrantes del triunvirato militar que dio golpe de Estado en 1978 al entonces presidente Juan Alberto Melgar, nombrado presidente en 1980 y quien convocó en 1981 a una Asamblea Nacional Constituyente para la formulación de una nueva Constitución de la república. 
esa época prevalecían en Honduras los gobiernos militares. Según el decreto de creación de la CONARE, sus funciones serán:

- Actuar como un órgano de comunicación entre el gobierno y el ACNUR.

- Para coordinar las actividades de los órganos de estado con el fin de dar asistencia a los refugiados.

- Para actuar como vínculo entre el gobierno y las ONGs.

- En concordancia con este decreto, CONARE emitió una regulación que enlista sus actividades siguiendo inter alia.

- Señalar las políticas generales para los refugiados;

- Para determinar el estatus basado en las definiciones de la ACNUR.

Como lo establecía el decreto, las funciones de las comisiones eran limitadas pues el gobierno era el encargado de crear las políticas, mientras que la ACNUR se encarga de la asistencia a los refugiados. A fin de entender el movimiento de refugiados propiciado por los conflictos armados existentes en El Salvador, Guatemala y Nicaragua se presenta la siguiente tabla:

\section{Tabla 1}

Refugiados Centroamericanos producto de la guerra contrainsurgente (1979-1986)

\begin{tabular}{lcccc}
\hline \multicolumn{1}{c}{ País de refugio } & Guatemaltecos & Salvadoreños & Nicaragüenses & Total \\
\hline Guatemala & - & 70,000 & 143 & 70,143 \\
El Salvador & - & - & - & - \\
Honduras & 1,000 & 20,000 & 25,000 & 46,000 \\
Nicaragua & $1,000^{*}$ & $17,000^{*}$ & - & 18,000 \\
Costa Rica & $1,000^{*}$ & 10,000 & $18,000^{*}$ & 29,000 \\
Panamá & $5^{*}$ & 1,000 & - & 1,005 \\
Belice & 3,000 & 7,000 & - & 10,000 \\
\hline TOTAL & 6,005 & 125,000 & 43,143 & 174,148 \\
\hline
\end{tabular}

Los datos con asterisco son estimaciones de la ACNUR

Fuente: The Central American refugee crisis a comparative study of the refugee situation and refugee policies of Costa Rica, Honduras and Nicaraguan (University of Oxford, 1988). Elaboración: Elvia Gómez 


\section{Refugiados nicaragüenses}

El triunfo de la revolución sandinista en Nicaragua y las posteriores acciones del gobierno revolucionario y de los grupos opositores al mismo desencadenaron un desplazamiento masivo de la población, que buscó refugio y asilo en los países vecinos de Honduras y Costa Rica. Debido a estos movimientos crecientes el Alto Comisionado de las Naciones Unidas para los Refugiados decidió establecer una oficina representante en Honduras, la cual se encargaría de servir como mediadora con el gobierno a fin de determinar las acciones a seguir para garantizar la protección y el trato humanitario, considerando que el gobierno hondureño no era suscriptor de la Convención ni el Protocolo sobre Refugiados de las Naciones Unidas. A partir de los estudios de campo realizados por los funcionarios de ACNUR, en su informe de la situación de los refugiados en el mundo (2000), este organismo aseveró que «El gobierno de Honduras, que dependía de la ayuda estadounidense, daba la bienvenida a los refugiados nicaragüenses que huían del gobierno sandinista, pero se mostraba muy suspicaz ante los refugiados salvadoreños» (p. 138). De igual forma estableció que: Aunque la mayoría de los refugiados reconocidos oficialmente como tales vivían en campamentos administrados por el ACNUR, las condiciones de dichos campamentos variaban considerablemente. Mientras los refugiados nicaragüenses podían salir y entrar de los suyos libremente, los salvadoreños se veían obligados a permanecer en campamentos cerrados, custodiados por las fuerzas armadas hondureñas. (p. 139)

Desde el año de 1981 cuando se creó el CONARE hasta 1987, que el gobierno de José Azcona del Hoyo suscribió un memorandum de entendimiento ${ }^{21}$ con el ACNUR para la regulación del tratamiento a los refugiados, las actividades tanto del ACNUR como de las ONGs interesadas en brindar alguna asistencia humanitaria estaban bajo la vigilancia de este ente.

En el caso particular de los refugiados nicaragüenses, los mismos fueron catalogados por el ACNUR en tres categorías, los refugiados misquitos, que fueron los mayoritarios, los ladinos y los ex guardias somocistas que se constituyeron en el grupo armado de la contra, estos últimos fueron los primeros en buscar refugio.

21 Un memorándum de entendimiento es la formalización por escrito de un acuerdo entre dos partes para expresar objetivos y líneas de acción comunes. 
7,000 ex guardias somocistas se ubicaron en los departamentos de Choluteca y El Paraíso en Honduras y en el vecino país de Costa Rica. Para 1981 aproximadamente 1,500 misquitos nicaragüenses se desplazaron a la Mosquitia hondureña, en el departamento de Gracias a Dios. Para 1982 el número incrementó de forma considerable, por lo que se estableció un campamento de refugiados en la comunidad de Mocorón y para ese mismo año los refugiados ladinos sumaban 2,500. El caso de los misquitos fue visto como un fenómeno atípico y como plantea el equipo de la revista Envío, en una investigación realizada en 1984, para el pueblo mískito nunca han existido fronteras nacionales ni dos países ni sentido de ciudadanía nicaragüense y hondureña. Su hábitat histórico y natural abarca parte del territorio de ambos países, en las dos riberas del Río Coco, la llamada Mosquitia. Se calcula que 14 mil mískitos, que habitualmente estaban establecidos del lado nicaragüense, están hoy en Honduras. Muchos de los misquitos eran reclutados para formar parte del grupo contrarrevolucionario MISURA ${ }^{22}$. Debido al incremento de refugiados ladinos, se dio la necesidad de instalar dos nuevos campamentos en las comunidades de Jacaleapa y Teupasenti, en el departamento de El Paraíso. Es importante en este punto hacer hincapié en la diferenciación establecida por el ACNUR pues los ex guardias somocistas se constituyeron, con la ayuda financiera de Estados Unidos y la complicidad de los gobiernos hondureños en el grupo armado denominado como «contras» ${ }^{23}$ y que los refugiados ladinos nicaragüenses provenían de diversos sectores sociales, algunos de ellos poseían el suficiente capital para instalarse en Honduras y arrendar casas en las comunidades cercanas a la zona fronteriza.

Sin embargo, la mayoría eran campesinos que buscaban refugio en el territorio huyendo de los combates que se daban entre los contras y los sandinistas ${ }^{24}$. La cantidad de refugiados en los campamentos establecidos para los nicaragüenses en Honduras llegó a ser de 10,000 en la comunidad

22 MISURA fue una guerrilla creada en 1981 conformada por la etnia miskita residente en Nicaragua y que operó a lo largo de la zona fronteriza con Honduras. Para mayor información consultar a Bataillon, 2015.

${ }^{23}$ Se define como contras al grupo armado conformado por diversas facciones que surge a raíz del triunfo de la revolución sandinista en Nicaragua. Para saber más puede consultar a Kruijt (2011).

${ }^{24}$ Sandinistas hace referencia a los miembros del ejército popular sandinista de Nicaragua. 
de Jacaleapa y 15,000 en la de Teupasenti. Era claro que al huir familias enteras en los campamentos se darían casos de nacimientos, los cuales fueron registrados por ACNUR y consignados como ciudadanos nicaragüenses.

En la medida en que los flujos de refugiados aumentaban, también se fue dando el hacinamiento de estos en los campamentos. Ingresaban al territorio no solo por los puntos fronterizos sino también por los diferentes puntos ciegos y, una vez en territorio hondureño, eran entregados por las autoridades nacionales a los representantes del ACNUR.

Para el caso, en 1983 trescientos refugiados nicaragüenses se encontraban hacinados en la comunidad de Trojes y los mismos fueron ubicados en la escuela a la espera de ser trasladados a los campamentos de refugiados manejados por el ACNUR. Este fue el mayor desplazamiento de población hasta la fecha que ingresó por un mismo punto fronterizo. Fueron recibidos por los pocos pobladores que aún quedaban en la comunidad y no recibieron ningún apoyo del gobierno, en lugar de ello los pobladores compartieron lo poco que tenían en alimentos con los recién llegados. Los elementos de las fuerzas armadas hondureñas eran los encargados de trasladar a los refugiados hacia los campamentos. Debemos apuntar también que en la medida en que el conflicto avanzaba se realizaban en la zona maniobras militares con presencia de elementos estadounidenses y las mismas tenían implícitas su labor social, que consistió en la llegada de brigadas médicas a las zonas de conflicto.

En el mapa que vemos a continuación podemos observar las zonas en las que estuvieron ubicados los campamentos de refugiados nicaragüenses, tanto en el departamento de El Paraíso como en el de Gracias a Dios, en el mismo se establece la diferenciación entre los refugiados miskitos y los refugiados ladinos 25

25 El término ladino se utiliza para referirse a aquellos refugiados que no pertenecen a ningún grupo étnico. 


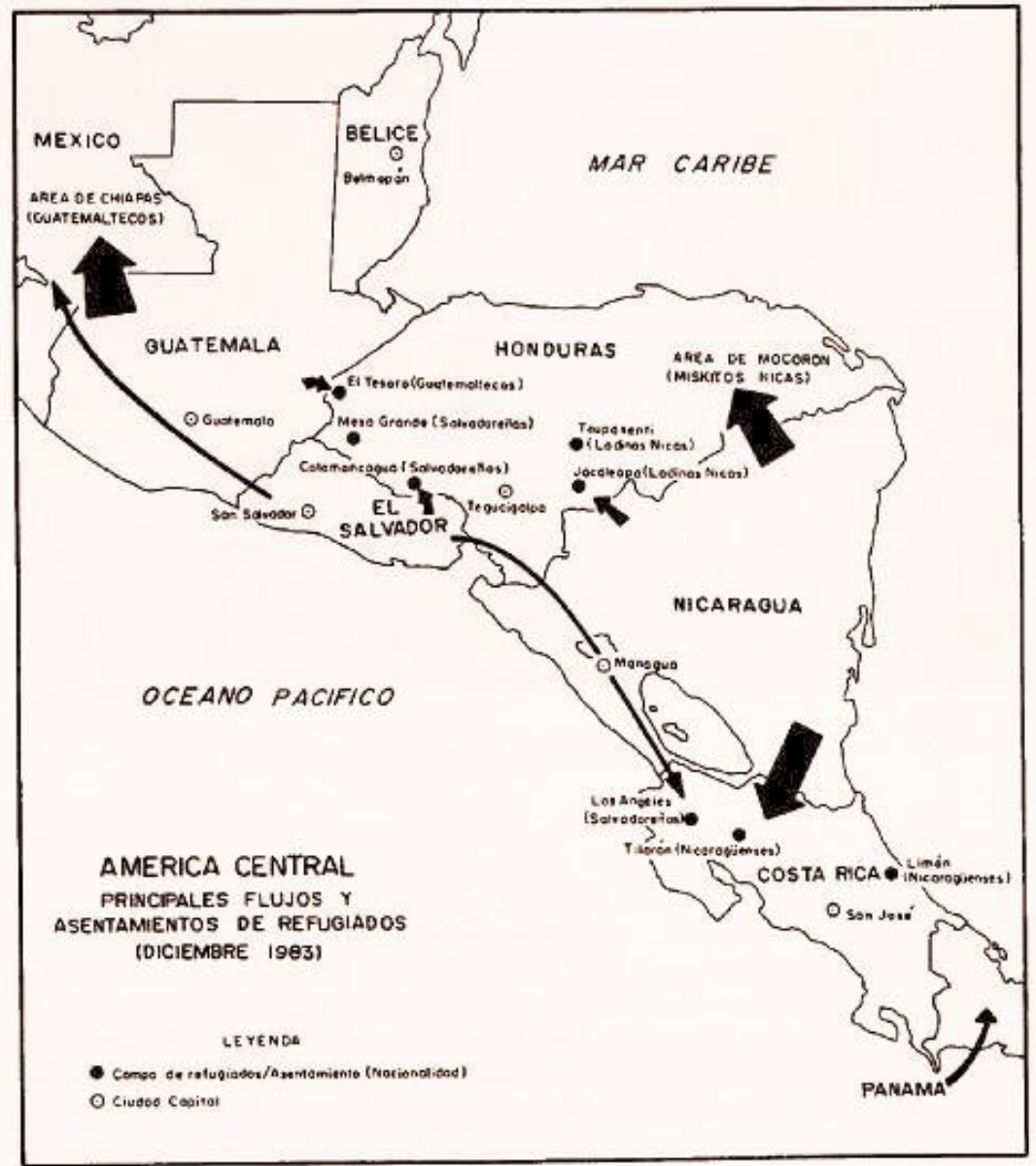

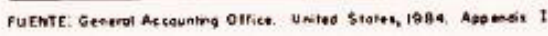

\section{Figura 1}

Mapa de ubicación de campamentos de refugiados en Honduras

Fuente: Historia General de Centroamérica, tomo VI, capítulo 3, p. 143.

Ante la problemática de los refugiados en Centroamérica y el incremento de los mismos, en 1984 se emitió la Declaración de Cartagena so- 
bre Refugiados adoptado por el Coloquio Sobre la Protección Internacional de los Refugiados en América Central, México y Panamá: Problemas Jurídicos y Humanitarios, en la cual se plantearon una serie de recomendaciones relacionadas con el tratamiento y la asistencia que debía brindarse a los mismos. Dentro de las conclusiones de dicho documento es conveniente citar la tercera que plantea (1984)

Reiterar que, en vista de la experiencia recogida con motivo de la afluencia masiva de refugiados en el área centroamericana, se hace necesario encarar la extensión del concepto de refugiado, teniendo en cuenta, en lo pertinente, y dentro de las características de la situación existente en la región, el precedente de la Convención de la OUA (artículo 1, párrafo 2) y la doctrina utilizada en los informes de la Comisión Interamericana de Derechos Humanos. De este modo, la definición o concepto de refugiado recomendable para su utilización en la región es aquella que además de contener los elementos de la Convención de 1951 y el Protocolo de 1967, considere también como refugiados a las personas que han huido de sus países porque su vida, seguridad o libertad han sido amenazadas por la violencia generalizada, la agresión extranjera, los conflictos internos, la violación masiva de los derechos humanos u otras circunstancias que hayan perturbado gravemente el orden público. (p. 3)

Dando seguimiento a lo planteado por la Declaración de Cartagena, en el acuerdo firmado por los presidentes de los cinco países centroamericanos «Procedimiento para establecer la paz firme y duradera en Centroamérica», celebrado en 1987 en la ciudad de Guatemala y conocido también como Esquipulas II, estos se comprometieron a buscar los mecanismos necesarios para la protección de los refugiados ante la comunidad internacional, a través de la firma de convenios bilaterales y multilaterales, así como del apoyo del ACNUR. De dicho acuerdo se desprendió la Conferencia Internacional sobre Refugiados Centroamericanos (CIREFCA) ${ }^{26}$, considera como refugiados a «las personas que han huido de sus países porque su vida, seguridad o libertad han sido amenazadas por la violencia generalizada, la agresión extranjera, los conflictos internos, la violación masiva de los derechos humanos $\mathrm{u}$ otras circunstancias que hayan perturbado gravemente el orden

${ }^{26}$ Surge como parte de las iniciativas de paz en Centroamérica en los acuerdos de Esquipulas. Para mayor información sobre el CIREFCA consultar http://www.acnur.org/ fileadmin/scripts/doc.php?file=fileadmin/Documentos/BDL/2011/1582 
público» (p. 9). De igual forma, plantea lo relacionado al asilo y reglas de protección, de tratamiento, de los campamentos y establecimientos de refugiados y las soluciones durables a la problemática ${ }^{27}$

\section{El éxodo hondureño: Las causas del desplazamiento}

Las implicaciones para las comunidades receptoras de los refugiados nicaragüenses y de los elementos contras fueron varias. Los pobladores comenzaron a manifestar un temor permanente producto de la libertad con la cual estos grupos armados se desplazaban por el territorio e ingresaban a los campamentos de refugiados en busca de nuevos reclutas dispuestos a unirse a sus filas. Los campamentos fueron utilizados como un puente para el abastecimiento de ayuda «humanitaria» al grupo armado, la cual provenía no solamente del gobierno norteamericano. Muchas ONGs que daban apoyo en la región y que, bajo el planteamiento de velar por la seguridad de los afectados, se dedicaron a cumplir una doble función pues escudados en la asistencia a las víctimas del conflicto, sirvieron también para canalizar la ayuda a los contras. En la tabla 2 se detallan algunas de las ONGs.

De igual forma asociaron el incremento de hechos delictivos a la presencia de los campamentos de refugiados pues en una zona caracterizada por su tranquilidad los pobladores se conocían entre sí. Las comunidades cercanas a la zona fronteriza con Nicaragua se vieron afectadas también por la naturaleza clandestina de las acciones llevadas a cabo por el grupo armado. Los derechos de los ciudadanos hondureños fueron violentados por este grupo que les exigía albergue en sus casas, les solicitaba alimentos, les robaba su ganado y asumieron actitudes como si fuesen autoridad en un país que no era el de ellos.

A raíz de estos acontecimientos algunos campesinos decidieron denunciar ante las autoridades los vejámenes de los cuales eran objeto, lo que lejos de solucionar la problemática desembocó en el desaparecimiento de muchos de ellos y tal como lo plantea una noticia publicada en el diario La Tribuna por Gómez (1982): «de acuerdo a información suministrada por familiares, los captores visten uniforme verde olivo con un monograma amarillo y blanco y portan armas de grueso calibre». (p. 3)

${ }_{27}$ Para mayor información puede consultar el documento «Principios y criterios para la protección y asistencia a los refugiados, repatriados y desplazados Centroamericanos en América Latina». < https://www.refworld.org.es/publisher,CIREFCA,,,57f7941f26,0.html> 
Refugiados nicaragüenses y desplazados en Honduras en la década de los ochenta

\section{Tabla 2}

Organizaciones de ayuda a la contra revolución nicaragüense

\begin{tabular}{|c|c|c|}
\hline Organización & Fundada & Observaciones \\
\hline $\begin{array}{l}\text { Amigos de la Libertad, Ministerios de } \\
\text { Fe Murray }\end{array}$ & 1985 & $\begin{array}{l}\text { Ayuda dirigida a los refugiados con } \\
\text { conexiones don el FDN }\end{array}$ \\
\hline Amigos de las Américas, Luisiana & 1984 & $\begin{array}{l}\text { Personajes como el diputado por } \\
\text { Luisiana }\end{array}$ \\
\hline $\begin{array}{l}\text { Asistencia civil de material, Memphis, } \\
\text { Tennessee }\end{array}$ & 1983 & $\begin{array}{l}\text { Ha tomado a cargo funciones } \\
\text { ejecutadas antes por la CIA }\end{array}$ \\
\hline $\begin{array}{l}\text { Asociación americana de luchadores por } \\
\text { la libertad }\end{array}$ & - & $\begin{array}{l}\text { Provee armas, munición, equipo y } \\
\text { personal mercenario a los contras }\end{array}$ \\
\hline Asociación del comando aéreo, Florida & 1968 & $\begin{array}{l}\text { Sus miembros son o fueron } \\
\text { miembros de las fuerzas especiales }\end{array}$ \\
\hline Auxilio internacional para refugiados, S.A & 1982 & Ayuda médica \\
\hline Auxilio médico mundial, Detroit & 1953 & $\begin{array}{l}\text { Mayor proveedor de trabajo } \\
\text { humanitario }\end{array}$ \\
\hline Brigada 2506, Miami & 1963 & Entrenamiento a contras \\
\hline $\begin{array}{l}\text { Confederación de asociaciones para la } \\
\text { Unificación de las Sociedades en las } \\
\text { Américas }\end{array}$ & 1980 & $\begin{array}{l}\text { Personajes como el embajador de } \\
\text { Estados Unidos en Honduras }\end{array}$ \\
\hline Ciudadanos por América & 1983 & $\begin{array}{l}\text { Esfuerzo en ganar apoyo del } \\
\text { congreso a los contras }\end{array}$ \\
\hline $\begin{array}{l}\text { Consejo estadounidense para la Libertad } \\
\text { Mundial }\end{array}$ & 1981 & $\begin{array}{l}\text { Una de las principales fuentes de } \\
\text { fondos a los contras }\end{array}$ \\
\hline Democracia Internacional & 1985 & $\begin{array}{l}\text { Ayudó a formar coalición de } \\
\text { guerrilleros anticomunistas }\end{array}$ \\
\hline Fondo para refugiados nicaragüenses & 1984 & $\begin{array}{l}\text { Integrado por personajes como el ex } \\
\text { embajador de Estados Unidos en Suiza }\end{array}$ \\
\hline Fondo para la libertad de Nicaragua & 1985 & Reunir fondos para los contras \\
\hline
\end{tabular}

Fuente: Barry, Tom. «Los humanitarios de la nueva derecha». Inter Hemispheric education resources center. Elaboración: Elvia Gómez 
Los secuestros realizados en la zona tenían como finalidad intimidar a los pobladores, a fin de que estos no denunciaran ni hicieran público lo que sucedía en la zona fronteriza. Los labriegos eran secuestrados y torturados, así quedó evidenciado en un reporte preliminar presentado por The Washington Office on Latin American (1986): «en enero de 1986 Ermenegildo Sánchez fue secuestrado, interrogado y liberado el mismo día... Ricardo Avilez no regresó a su casa. Cinco días después su cuerpo fue encontrado por Santos Pérez, quien se convirtió en secuestrado». (p. 4)

En la medida en que se iban apropiando de las poblaciones donde ubicaron sus campamentos, los contras iban ejerciendo un estricto control sobre las comunidades, llegando a extender permisos o salvo conductos para que las personas pudieran circular. También llevaron a cabo detenciones ilegales utilizando como argumento que los detenidos daban información al ejército popular sandinista sobre los movimientos que hacía la contra. Ante tales hechos, los pobladores se organizaron en Comités de la Defensa Civil, pero de poco les sirvió hacerlo pues las autoridades hondureñas eran juez y parte de todo lo que acontecía. Otra de las actividades que contribuyó a los desplazamientos masivos de población fueron los constantes combates e incursiones al territorio nicaragüense realizados desde la zona fronteriza hondureña.

Las constantes «mortereadas», como calificaron los pobladores a los lanzamientos de morteros hacia las zonas de combate tanto del lado hondureño como del nicaragüense, obligaron a los pobladores a construir barricadas a fin de poder escapar de los constantes bombardeos. Los contras se dedicaron a «sembrar» minas a lo largo de la línea fronteriza con Nicaragua, con la finalidad de evitar las incursiones del ejército popular sandinista sin tomar en consideración que cualquiera de los pobladores podía ser víctima de estas. No existe un mapa que indique el lugar exacto en el cual fueron colocadas las mismas y esto acrecentó más el temor de los pobladores. Existen víctimas de estas minas antipersonales que perdieron algún miembro de su cuerpo como producto de la explosión de las mismas al ser pisadas mientras realizaban sus faenas en el campo. El ganado también caía en estas minas y significaba pérdidas económicas para los habitantes de la zona.

\section{Desplazados}

La Conferencia Internacional sobre refugiados Centroamericanos estableció que: Aunque no existe una definición generalmente aceptada, se han 
considerado desplazados a las personas que han sido obligadas a abandonar sus hogares o actividades económicas habituales debido a que su vida, seguridad o libertad han sido amenazadas por la violencia generalizada o el conflicto prevaleciente, pero que han permanecido dentro de sus países. (p. 25)

Los desplazados no podían ser atendidos por el ACNUR por lo que su situación era más delicada pues no estaban contemplados en ninguno de los documentos que hasta el momento se habían emitido en torno a la problemática regional. De igual forma las comisiones creadas por el gobierno hondureño no contemplaban esta problemática pues estaban enfocadas en la atención a los refugiados. La Conferencia establece que:

La responsabilidad primaria de atender a las personas desplazadas compete al Estado, puesto que son sus nacionales y se encuentran en su propio territorio. Sin embargo, las posibilidades de los Estados de la región para hacer frente a las necesidades de las personas desplazadas pueden ser extremadamente limitadas, ya que los recursos con que cuentan son escasos y la ayuda internacional no va dirigida especialmente a esta categoría de personas. (p. 24)

Huyendo de los constantes enfrentamientos entre los bandos de la contra y los sandinistas y de las violaciones a los derechos humanos perpetradas por los primeros hacia la población civil hondureña, miles de familias abandonaron sus hogares y buscaron refugio en las comunidades vecinas a partir de 1982. El gobierno negaba constantemente la existencia de los mismos y no se habilitaron por parte de este ningún tipo de albergues ni centros de acogida; inclusive en las estadísticas existentes de la época no observamos que se contemple en los datos manejados por organismos como el ACNUR el de las poblaciones desplazadas. Si bien toda la zona fronteriza hondureño nicaragüense se encontraba bajo amenaza por los constantes enfrentamientos, será el departamento de El Paraíso el mayor afectado, pues la mayoría de los campamentos contras se encontraban en esta región. El hecho de que los pobladores fronterizos y en especial los del que se constituyó en municipio en 1987, Trojes (anteriormente formaba parte del municipio de Danlí), acogieran a los ex guardias somocistas pensando que los protegerían de la amenaza del comunismo, sin considerar las consecuencias que su apoyo traería a la región, agudizó la problemática.

Comunidades enteras se vieron desplazadas y entre las mismas podemos mencionar Arenales, Español Grande, Españolito, Zepeda, Yamales, La Fortuna, Altos del Poteca, Maquengales, Las Trojes, Cifuentes y Pla- 
nes de Cifuentes en el municipio de Trojes; sectores de Las Limas en el municipio de Alauca; La Lodosa, Cedrales, Las Selvas, El Recuerdo en el municipio de El Paraíso.

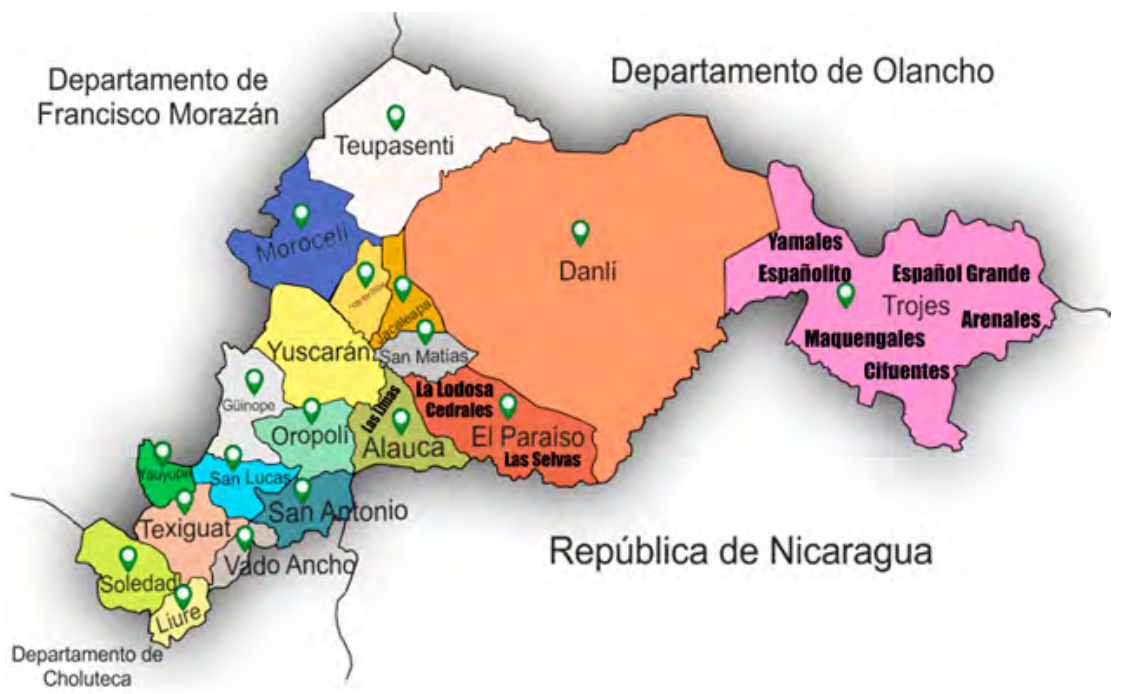

Figura 2

Comunidades de marcado desplazamiento

Fuente: <https://www.espaciohonduras.net/division-politica/departamento-de-el-paraiso> [10/11/2018] Elaboración: Elvia Gómez

Cuando tomaron la decisión de salir de sus hogares el destino escogido fue diverso, muchos de ellos optaron por vivir con sus familiares en el municipio de Danlí y el valle de Jamastrán, otros se desplazaron hacia El Paraíso y otros huyeron al departamento de Colón con sus pertenencias y animales y no regresaron más. Entre los desplazados encontramos a cafetaleros que vieron la pérdida de sus cultivos, la Asociación Hondureña de productores de café (AHPROCAFE) ${ }^{28}$ a través de su vicepresidente

28 AHPROCAFE Es una organización gremial sin fines de lucro al servicio de los productores y productoras de café hondureños/as creada el 03 de agosto del año de 1967. Para mayor información puede consultar https://www.fondocafetero.com/ahprocafe 
realizó una visita de inspección a la región y según el boletín publicado por el Centro de Documentación de Honduras CEDOH (1998)

Constatamos que, como consecuencia de los constantes enfrentamientos entre los contras y las tropas sandinistas, un total de 34 aldeas han sido completamente abandonadas por sus habitantes y la situación tiende a empeorarse cada día más. La mayoría de los desplazados buscan refugio en Las Trojes. El 70\% de familias desplazadas son productores de café. En Las Trojes los desplazados viven en condiciones infrahumanas, dándose el caso de que en una vivienda permanecen hasta 14 familias. (p. 3)

Los desplazados por su parte iban en aumento y la asistencia del gobierno era mínima, para el caso en 1986 se destinaron 5,000 lempiras para asistir a 426 familias con un promedio de 5 a 7 miembros cada una. Los pobladores que fueron víctimas del desplazamiento, aún después de finalizado el conflicto, mantienen fresco en sus recuerdos lo vivido, Andrés Martínez quien fue el jefe del Comité de la Defensa Civil en Las Trojes recuerda que del gobierno no recibieron nada, que las promesas de los presidentes de turno fueron solo eso, promesas y como nos lo expresó en una entrevista: «Puede imaginarse como nos sentíamos nosotros, nos sentíamos como si estuviéramos en una zona que no fuera de nadie, infinidad de veces lo dijimos al congreso, al presidente si prácticamente esta zona era de Nicaragua que nos dijeran para irnos de este lugar, porque aquí quien mandaba era prácticamente la contrarrevolución».

\section{Acciones de asistencia a desplazados}

Invisibles para las autoridades nacionales que no admitían su existencia, los desplazados hondureños quedaron a su suerte y en la medida en que el número fue en aumento algunas organizaciones como CARITAS ${ }^{29}$ de Honduras, la Agencia Internacional para el Desarrollo (AID) y personas particulares comenzaron a manifestar su preocupación y a buscar mecanismos de asistencia para los desplazados. En 1985 el entonces embajador de Honduras John Negroponte entregó un cheque a la organización

${ }^{29}$ CARITAS fue creada por acuerdo episcopal en 1959 y en la década de los ochentas se dedicó a la defensa de los derechos humanos y la atención a los refugiados en Honduras. Para mayor información visite http://www.caritashonduras.org/. 
CARITAS de Honduras, según lo informado en un boletín del $\mathrm{CEDOH}$ (1988):

Tengo la satisfacción de entregar al señor Francisco Meraz, director de CARITAS este cheque del gobierno de los EEUU por 25,000 dólares para ayudar con la compra de alimentos, medicinas y ropa a los desplazados que se encuentran en el departamento de El Paraíso. Estos se vieron obligados a dejar sus hogares a principios de este mes porque temían por sus vidas, pero se prometieron valientemente no ser intimidados a dejar su región de origen hasta que puedan ser reubicados en circunstancias más seguras, estas víctimas de la agresión nicaragüense necesitan ayuda humanitaria de urgencia. (p. 2)

Las declaraciones evidencian que solamente se consideró una cara de la moneda al señalar que los culpables de los desplazamientos eran los ataques de los sandinistas. En ese año, el gobierno hondureño seguía negando la existencia de los contras y sus operaciones en territorio nacional. Para el año de 1986 y bajo el mandato de un nuevo presidente el número de desplazados de guerra hondureños había aumentado considerablemente, en una noticia publicada en marzo de 1986 en el diario La Tribuna y citada en el boletín No 10 del mes de octubre del CEDOH dedicado a los desplazados de guerra hondureños, se planteó que la cifra ascendía a 17,000 personas, según estimaciones. No hay estadísticas oficiales de parte del gobierno y su situación iba en constante detrimento debido al hacinamiento en el cual se encontraban en las comunidades donde se desplazaban, pues eran sus mismos familiares o amigos quienes los acogían en sus casas.

La asistencia médica era manejada por el hospital público de Danlí con ayuda del Dr. Denis Castro, quien inclusive consiguió helicópteros para movilizarse a la zona fronteriza llevando brigadas médicas. De igual forma el periodista Luis Alonso Gómez hizo gestiones con el ejército a través de la 110 brigada, formada por las unidades del noveno batallón de infantería afincado en Jamastrán y el sexto batallón que atendía las áreas de Danlí, El Paraíso y Alauca. En palabras del periodista Gómez (2015)

De cierta forma el ejército escuchó las denuncias de los desplazados y brindó algún tipo de ayuda, se sabe que un alto oficial de las fuerzas armadas hondureñas, comandante de una de las brigadas tuvo contacto con el Coronel Bermúdez de la contra exigiéndole el cese de hostilidades en contra de los civiles nacionales que vivan en las comunidades cercanas a los campamentos donde ellos estaban ubicados. 
El gobierno prometió la construcción de una carretera de emergencia que permitiera a los pobladores de las zonas en conflicto salir de las mismas y desplazarse al interior del país, el proyecto quedó en el olvido y el acceso a la zona era sumamente complicado. Tanto refugiados como desplazados fueron víctimas de una época convulsionada de la historia centroamericana. Los primeros acogidos por el ACNUR y los segundos a la espera de la ayuda de las autoridades nacionales. Los primeros con más privilegios que no se tradujeron en una mejora significativa en sus condiciones de asilo comparados a los segundos, pero si con mayor asistencia de parte del gobierno. Las políticas implementadas en la época se fueron transformando en la medida que el conflicto iba avanzando. En 1983 se creó lo que se denominó como el grupo de CONTADORA ${ }^{30}$, conformado por México, Colombia, Venezuela y Panamá con la finalidad de promover la paz en Centroamérica. Dentro de las temáticas manejadas por el grupo se encontraba la problemática de los refugiados de guerra. Dando seguimiento al trabajo realizado por el grupo de CONTADORA, en 1984 se celebró un coloquio en Cartagena, Colombia en el cual se hizo un llamado a los países a adoptar los acuerdos internacionales existentes en materia de refugiados y se emitió un documento que retoma lo planteado en el acta de CONTADORA.

La Declaración de Cartagena sobre Refugiados estableció, entre otros puntos lo siguiente:

Sexta: Reiterar a los países de asilo la conveniencia de que los campamentos y asentamientos de los refugiados ubicados en zonas fronterizas sean instalados al interior de los países de asilo a una distancia razonable de las fronteras con miras a mejorar las condiciones de protección a favor de estos, a preservar sus derechos humanos y a poner en práctica proyectos destinados a la autosuficiencia e integración en la sociedad que los acoge. Novena: Expresar su preocupación por la situación que padecen las personas desplazadas dentro de su propio país. Al respecto, el Coloquio llama la atención de las autoridades nacionales y de los organismos internacionales competentes para que ofrezcan protección y asistencia a estas personas y contribuyan a aliviar la angustiosa situación en que muchas de ellas se encuentran. (pp. 3 y 4)

30 El Grupo CONTADORA fue una instancia multilateral propuesta en enero de 1983 por México, Venezuela, Colombia y Panamá para buscar una solución pacífica al conflicto centroamericano. Para más información puede consultar en https://acuerdosdepaz.wordpress.com/2012/06/09/contadora/ 
Las iniciativas internacionales sirvieron para dar voz a las víctimas del conflicto y para presionar a los gobiernos de turno a iniciar las negociaciones que condujeran a su resolución. De las gestiones del grupo de CONTADORA se desprendió el Acta de Contadora de 1986, de la cual se destacan algunos elementos contenidos en el capítulo 4, sección 2 y que se citan a continuación:

Las Partes se comprometen a llevar a cabo los esfuerzos necesarios con miras a: 60. Realizar, si aún no lo han hecho, los trámites constitucionales para adherirse a la Convención de 1951 sobre el Estatuto de los Refugiados y al Protocolo de 1967 sobre el Estatuto de los Refugiados. 61. Adoptar la terminología establecida en la Convención y en el Protocolo citados en el párrafo anterior, con el objeto de diferenciar a los refugiados de otras categorías de migrantes.62. Establecer, cuando se produzca la adhesión, los mecanismos internos necesarios para aplicarlas disposiciones de la Convención y del Protocolo citados en el numeral 58. 63.Establecer mecanismos de consulta entre los países centroamericanos con representantes de las oficinas gubernamentales responsables de atender el problema de los refugiados en cada Estado.64. Apoyar la labor que realiza el Alto Comisionado de las Naciones Unidas para Refugiados(ACNUR) en Centroamérica, y establecer mecanismos directos de coordinación para facilitar el cumplimiento de su mandato.65. Que toda repatriación de refugiados sea de carácter voluntario, manifestada individualmente y con la colaboración del ACNUR. 66.Que, con el objeto de facilitar la repatriación de los refugiados, se establezcan comisiones tripartitas integradas por representantes del Estado de origen, el Estado receptor y el ACNUR.67. Fortalecer los programas de protección y asistencia a los refugiados, sobre todo en los aspectos de salud, educación, trabajo y seguridad.68. Que se establezcan programas y proyectos con miras a la autosuficiencia de los refugiados. (p. 18)

Desde 1983 y hasta 1987 pese a todas las reuniones, gestiones y entendimientos que se desprendieron de las mismas, ninguna de ellas logró sus objetivos, pero la situación mundial se iba transformando, los conflictos desgastándose y esto creó las condiciones para el surgimiento de las iniciativas de paz a partir de las cumbres presidenciales. Honduras en particular siempre buscó una falla en estas iniciativas, manifestaba su desacuerdo con todo lo que se planteaba en los documentos y pedía nuevas revisiones de los mismos con la finalidad de alargar la firma y la entrada en vigencia de las propuestas. 
Mientras esto sucedía, tanto refugiados como desplazados pasaron por situaciones adversas y estuvieron en condiciones precarias. Su número en lugar de disminuir iba en ascenso y las respuestas gubernamentales hacia los desplazados no fueron lo que los pobladores esperaban. Hacinamiento, marginación, pobreza, hambre, enfermedades, violaciones a los derechos humanos por parte de las autoridades nacionales, así como de los contras y la indiferencia fueron el diario vivir. La asistencia brindada a los desplazados fue de parte de organizaciones no estatales como la Cruz roja, Amigos de las Américas, la AID y CARITAS de Honduras.

\section{A manera de conclusiones}

1.- Los conflictos armados a lo interno de Guatemala, Nicaragua y El Salvador provocaron movimientos masivos de personas en busca de seguridad y protección. Estas poblaciones optaron por desplazamientos a lo interno de sus países y otros decidieron buscar refugio en países vecinos como Honduras. Aquellos que salieron de su territorio, se convirtieron en refugiados y fueron acogidos bajo la asistencia del Alto Comisionado de las Naciones Unidas para los Refugiados, que envió representantes permanentes encargados de velar por su protección y organizar, junto con las autoridades hondureñas los campamentos en los cuales serían ubicados. Sin embargo, el trato dado por las autoridades nacionales a los refugiados nicaragüenses fue muy diferente al que recibieron los salvadoreños, tal como lo manifestaron los mismos representantes del ACNUR. Existía un recelo infundado hacia los salvadoreños a quienes se acusaba de ser cómplices de la guerrilla, mientras que los nicaragüenses podían deambular libremente por las comunidades donde estuvieron ubicados.

2.- Dentro de las leyes vigentes en Honduras en la década de los ochentas, ni la Constitución de la República ni la Ley de Población y Política Migratoria, incluían en su contenido artículos que utilizaran los términos de refugiado y desplazado. Tampoco había hecho adhesión a la convención y el protocolo sobre los refugiados del ACNUR. Lo anterior, dejaba a criterio de las autoridades las acciones viables y quedaba, por ende, el compromiso que los gobiernos de Policarpo Paz García, Roberto Suazo Córdova y José Simón Azcona del Hoyo en su orden, pudiesen asumir en esta materia a través de los mecanismos pertinentes como tratados e iniciativas. Lo anterior es de vital importancia para comprender el porque de un trato diferenciado entre el refugiado salvadoreño y el nica- 
ragüense. Al producirse la llegada de los primeros refugiados, el gobierno del entonces presidente Policarpo Paz García conformó la Comisión Nacional para los refugiados, la cual coordinó las acciones con el ACNUR y las ONGs encargadas de brindar asistencia, teniendo en consideración que la misma se limitaba a lo que el gobierno permitiese.

3.- La atención a los desplazados no estaban definida dentro de las funciones del ACNUR y fue hasta que se conformó la Conferencia Internacional sobre Refugiados Centroamericanos CIREFCA en 1989, que los mismos adquirieron visibilidad. Ante tal situación, estaban sujetos a la voluntad de las autoridades nacionales y la asistencia que organizaciones no gubernamentales pudiesen ofrecer para mejorar su condición. Con relación a los desplazados hondureños, fue el departamento de El Paraíso el más afectado y la ciudad de Danlí se convirtió en el centro de acogida de los mismos. Las condiciones de alojamiento fueron de hacinamiento y los pobladores de la ciudad, junto con CARITAS de Honduras y el gobierno municipal brindaron la asistencia que los recursos con que contaban les permitió en esos momentos. El gobierno negó su existencia pues aceptarla implicaba reconocer también la presencia del grupo armado de los contras en el territorio, cuyas acciones fueron las que provocaron el desplazamiento interno.

\section{Fuentes}

Acta de Contadora para la paz y la cooperación en Centroamérica. Ciudad de Panamá, 6 de junio de 1986. <https://www.acnur.org/fileadmin/Documentos/BDL/2002/1566.pdf?file=fileadmin/Documentos/BDL/2002/1566>. [10/01/2015]

ACNUR. Convención sobre el estatuto de los refugiados. Ginebra, 1951, < https://www.acnur.org/5b0766944.pdf>. [10/01/2015]

ACNUR. Protocolo sobre el estatuto de los refugiados. Nueva York, 1967, < https://www.acnur.org/5b076dcd4.pdf>. [10/01/2015]

ALONSO SANTOS, J. (1992-1993). Los desplazamientos forzados de población en la crisis centroamericana de los años ochenta. Boletín de la AGEN, 63-87.

ASAMBLEA NACIONAL CONSTITUYENTE, "Constitución de la república de Honduras», Tegucigalpa, 1981, <http://www.poderjudicial.gob. $\mathrm{hn} /$ CEDIJ/Leyes/Documents/Constituci\%C3\%B3n\%20de\%201a\%20 Rep\%C3\%BAblica\%20de\%20Honduras\%20\%28Actualizada\%202014\%29. pdf> [12/03/2015

BARRY, Tom, «Los humanitarios de la nueva derecha», Inter-hemispheric Education Resources Center, CEDOH, Tegucigalpa, código 393. 
CEDOH. «Desplazados de guerra hondureños», Boletín CEDOH, \#10, octubre 1988. CIREFCA, «Documento de la república de Honduras: Diagnóstico, estrategia y propuestas de proyecto», febrero 1989, < https://www.refworld.org.es/ pdfid/5ab02ea94.pdf $>$ [12/03/2015]

CIREFCA. «Principios y criterios para la protección y asistencia a los refugiados, repatriados y desplazados centroamericanos en América Latina», Guatemala, 1989, < https://www.acnur.org/fileadmin/Documentos/ BDL/2011/1582.pdf $>$ [20/01/2015]

COLOQUIO SOBRE LA PROTECCIÓN INTERNACIONAL DE LOS REFUGIADOS EN AMÉRICA CENTRAL, MÉXICO Y PANAMÁ: PROBLEMAS JURÍDICOS Y HUMANITARIOS. «Declaración de Cartagena sobre refugiados». Cartagena, Colombia, 1984, <https:/www.acnur.org/ fileadmin/Documentos/BDL/2002/1566.pdf?file=fileadmin/Documentos/ BDL/2002/1566> [ 15/02/2015]

COMMITTEE ON FOREIGN AFFAIRS, U.S. HOUSE OF REPRESENTATIVES, «The Current Situation in Honduras and U.S. Policy,» Statement before the Subcommittee on Western Hemisphere Affairs, Washington, DC, March 15, 1983 (testimony of 33 pages).

CONGRESO NACIONAL DE HONDURAS. «Constitución de la república de Honduras», Tegucigalpa, 1965, < http://www .cervantesvirtual.com/obra-visor/constitucion-de-honduras-de-1936-0/html> [17/03/2015]

CONGRESO NACIONAL DE HONDURAS, Decreto \#34 «Ley de población y política migratoria». Tegucigalpa, MDC, 1970, <http://www.poderjudicial. gob.hn/CEDIJ/Leyes/Documents/LeyPoblacionyPoliticaMigratoria.pdf> [20/01/2015]

GÓMEZ, Luis, «Grupos armados desaparecen campesinos en El Paraíso: uno es hallado muerto». Diario La Tribuna,18 de agosto de 1982, p. 3.

GÓMEZ, Luis, «Por oleadas llegan nicas a El Paraíso». Diario La Tribuna,20 de noviembre de 1982, p. 5.

GÓMEZ, Luis, «Abandono en la zona fronteriza». Diario La Tribuna,6 de febrero de 1984, p. 15.

GÓMEZ, Luis, «Los refugiados y desplazados». (E.E. Gómez, Entrevistador). 22 de diciembre del 2015.

MARTINEZ, Andrés. La presencia de los contras y sus consecuencias. (E.E. Gómez, Entrevistador). Enero de 1995. Entrevista.

PROYECTO DE MIGRACIÓN HEMISFÉRICA, «Informe sobre la situación de los refugiados y migrantes centroamericanos». 1985. CEDOH, código 2735.

SECRETARÍA DE ESTADO EN EL DESPACHO DE GOBERNACIÓN Y JUSTICIA, «Decreto \#13», Tegucigalpa, 1981. CEDOH, código 2671.

THE WASHINGTON OFFICE ON LATIN AMERICAN, "The contras human rights abuses against Honduran civilians, preliminary report», Washington, D.C.,1986. 
UNIVERSITY OF OXFORD, «The Central American Refugee crisis a comparative study of the refugee situation and refugee policies of Costa Rica, Honduras and Nicaraguan», 1988, CEDOH, código 2707.

\section{Bibliografía}

ACNUR. LA SITUACIÓN DE LOS REFUGIADOS EN EL MUNDO, 2000, cincuenta años de acción humanitaria. (B. Wang \& F. Chueca, trads.), Barcelona, Edit. Icaria, 2000.

AGNEW, John «Geopolítica, una revisión de la política mundial», editorial Trama, España, 2005.

Aguayo, S. (Abril de 1985). Exodo Centroamericano. Nexos, 8(88), 37-43.

AlEgRÍA, Claribel y FlaKoll, D. J., «Nicaragua: La revolución sandinista. Una crónica política /1855-1979», Ediciones Era, México D.F, 1982.

BataILlon, Gilles, «Crónica sobre una guerrilla: Nicaragua 1982-2007», CIDES, México, 2015.

EQUiPO ENVío, «Una de las caras de la guerra: Refugiados y desplazados en Centroamérica», Revista Envío, \#33, 1984, <http://www.envio.org.ni/ articulo/415> [ 16/04/205]

FigueroA, Carlos, «Centroamérica: Entre la crisis y la esperanza (1978-1990)» en TORRES, Edelberto, «Historia Inmediata», volumen 6., Editorial FLACSO, Costa Rica, 1994.

KRAUSE, Walter, «La alianza para el progreso», Journal of Inter-American Studies Vol. 5, No. 1, January 1963, pp. 67-81

KRUIJT, Dirk, «Revolución y contrarrevolución: el gobierno sandinista y la guerra de la Contra en Nicaragua, 1980-1990». Desafíos 23-II, 2011, pp. 53-81.

LEAL, Francisco. «La doctrina de seguridad nacional: Materialización de la guerra fría en América del Sur», Revista de Estudios Sociales, No 15 (2003): 74-87. <https://doi.org/10.7440/res15.2003.05> [21/01/2017]

NinKovich, Frank, "The Diplomacy of ideas. U.S, foreign policy and cultural relations, 1938 1950», Edit. Cambridge University Press. 1981.

PisanI, Francis, «Muchachos: Nicaragua: Diario de un testigo de la revolución sandinista», editorial Planeta, Barcelona, 1981.

POSAS, Mario, «Modalidades del proceso de democratización en Honduras», Editorial Universitaria, Tegucigalpa, 1989.

TORRES, Edelberto, «Introducción a la época» en TORRES, Edelberto, «Historia Inmediata», volumen 6. Editorial FLACSO, Costa Rica, 1994.

TOVAR, Juan, «Cuatro momentos de la doctrina en política exterior estadounidense: ¿Entre la teoría y la práctica?», CIDOB d'afers internacionals, $\mathrm{n}^{\circ} 95$, septiembre 2011, p. 165-187.

VILAS, Carlos, «Democracia emergente en Centroamérica», Editorial UNAM, México, 1993. 


\section{Datos de la autora}

Elvia Elisabeth Gómez García licenciada en Historia por la Universidad Nacional Autónoma de Honduras UNAH. Máster en Historia y Humanidades Digitales por la Universidad Pablo de Olavide, Sevilla (España). Experto Universitario en Memoria Social y Derechos Humanos por la UNED, España. Docente universitaria y Jefa académica de Humanidades en la Universidad Tecnológica Centroamericana UNITEC Honduras en su campus San Pedro Sula. 